\title{
Carbon emission assessment of wastewater treatment plant based on accounting perspective
}

\author{
Lin Lin \\ Jilin City Radio and Television University, 132000Jilin, China
}

\begin{abstract}
Excessive GHG emissions from human activities lead to climate warming, and sewage treatment plants are one of the sources of GHG emissions. The number of sewage treatment plants in my country is increasing year by year, and they emit a large amount of GHG, it is necessary to evaluate their emissions and seek ways to reduce emissions. According to the "Greenhouse Gas Inventory ProtocolCorporate Accounting and Reporting Standards", taking a sewage treatment plant in a northern city as an example, the GHG emission classification of its operation control range, selection of evaluation methods and emission factors, assessment of GHG emissions, analysis of GHG emissions Constitution, propose ecological treatment technology, recycling $\mathrm{CH}_{4}$ and other emission reduction measures.
\end{abstract}

The excessive emission of greenhouse gases such as $\mathrm{CO}_{2}, \mathrm{CH}_{4}$ and $\mathrm{N}_{2} \mathrm{O}$ into the atmosphere by human activities has led to environmental problems such as climate warming, this has led to international agreements and cooperation on GHG emission reductions, including the Kyoto Protocol. Sewage treatment plants are recognized as one of the main sources of GHG emissions [1]. Sewage treatment plants directly emit $\mathrm{CO}_{2}, \mathrm{CH}_{4}, \mathrm{~N}_{2} \mathrm{O}$ and other greenhouse gases in the process of sewage treatment, and the energy and materials consumed indirectly generate greenhouse gases.

In recent years, with my country's economic growth and emphasis on environmental protection, my country's urban sewage discharge, the number of sewage treatment plants, and sewage treatment capacity have continued to rise. In 2016, the national urban sewage discharge volume was 4,803.49 million $\mathrm{m}^{3}$, the sewage treatment plants were 2,039 , the sewage treatment capacity was 14.095 million $\mathrm{m}^{3} / \mathrm{d}$, and the sewage treatment capacity was 43131.15 million $\mathrm{m}^{3}$ [2]. Many sewage treatment plants emit a large amount of GHG in operation, however, the carbon emission assessment of sewage treatment plants is relatively rare in my country and is still in the exploratory stage.

According to related research, according to the IPCC agreement, $\mathrm{CO}_{2}$ emissions in wastewater are of biological origin and are not included in the total emissions, IPCC recommended methods are adopted by most researchers. Most studies believe that the carbon emissions of sewage treatment plants are divided into two parts: one is the direct emission of greenhouse gases such as $\mathrm{CO}_{2}, \mathrm{CH}_{4}$ and $\mathrm{N}_{2} \mathrm{O}$ in the process of sewage treatment; the other is the indirect emission caused by the energy and materials consumed in operation. There are also studies that divide the carbon emission system of the sewage treatment system into five aspects: material, energy, material consumption, carbon sink and resource [3]. Few studies have focused on factors such as $\mathrm{CO}_{2}, \mathrm{CH}_{4}$, and $\mathrm{N}_{2} \mathrm{O}$ GHG emissions.

This article takes a sewage treatment plant in a northern city as an example, analyzes the GHG emissions of each link in its operation process, objectively and comprehensively reports GHG emissions, analyzes the influencing factors of GHG emissions, and provides a reference for the carbon emission accounting and supervision of the sewage treatment plant, provide reliable information for energy conservation, emission reduction and environmental protection.

\section{Research methods}

The Greenhouse Gas Inventory Protocol-Corporate Accounting and Reporting Standards is a set of internationally recognized greenhouse gas (GHG) accounting and reporting standards developed by the World Business Sustainability Association (WBCSD) and the World Resources Institute (WRI) for companies, the purpose is to truly and fairly reflect the company's greenhouse gas emissions, simplify and reduce the cost of compiling a greenhouse gas inventory, and gain wide acceptance and adoption by companies, non-governmental organizations and government agencies around the world. [4] According to the "Greenhouse Gas Inventory Protocol-Corporate Accounting and Reporting Standards", take the current AAO treatment process commonly used in urban sewage treatment plants as an example: 


\subsection{Evaluation scope}

Use the operation control method to determine the scope of GHG assessment of the sewage treatment plant, the raw GHG emissions must be $100 \%$ identified, and the emissions related to sewage treatment must be identified and classified, as shown in Figure 1.

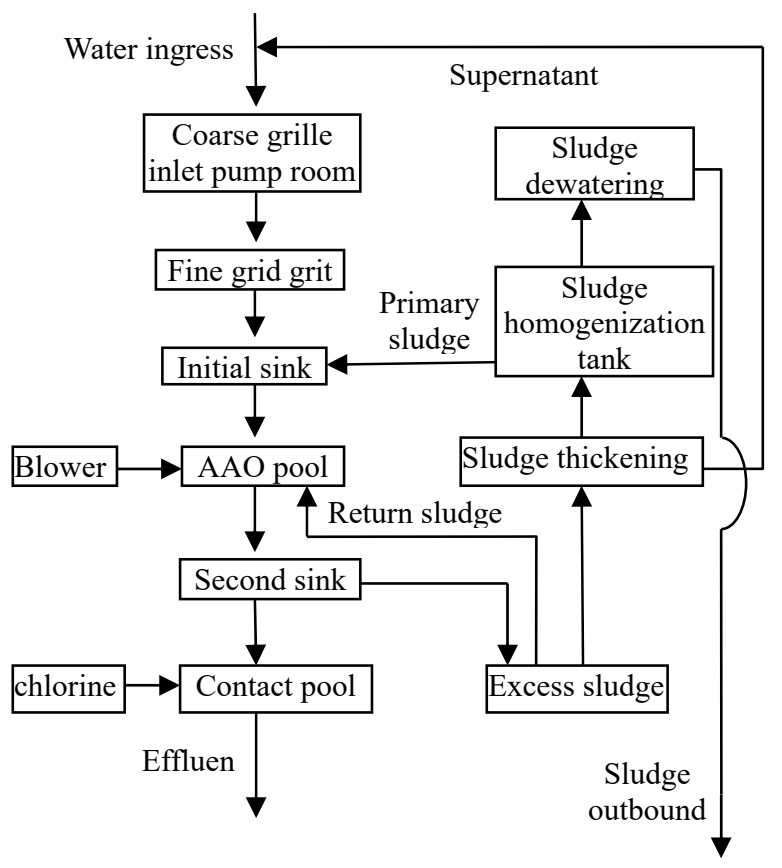

Fig. 1. Sewage treatment plant assessment scope boundary

The carbon emissions of sewage treatment plants are divided into three parts: direct emissions, indirect emissions, and other indirect emissions.

Direct discharge. Direct GHG emissions from sewage treatment plants are mainly $\mathrm{CO}_{2}$ from the aerobic decomposition and conversion of organic matter in the biological treatment process, $\mathrm{CO}_{2}$ and $\mathrm{CH}_{4}$ from the anaerobic digestion process, $\mathrm{N}_{2} \mathrm{O}$ from the denitrification process, and direct emissions from other links.

Indirect emissions. The purchased electricity consumed by the operation of blowers, pumps, aerators and other equipment in the sewage treatment plant generates indirect emissions.

Other indirect emissions. Indirect GHG emissions from the purchased medicines, purchased raw materials, and fuel transportation consumed by the sewage treatment plant.

\subsection{Assessment method}

The $\mathrm{CO}_{2}, \mathrm{CH}_{4}, \mathrm{~N}_{2} \mathrm{O}$ and other greenhouse gases emitted by the sewage treatment plant are uniformly measured by the amount of $\mathrm{CO}_{2}$ produced. According to the global warming potential (GWP), the potential value of $\mathrm{CO}_{2}$ is 1 , and the potential values of $\mathrm{CH}_{4}$ and $\mathrm{N}_{2} \mathrm{O}$ are 23 and 296 respectively [5], $\mathrm{CH}_{4}$ and $\mathrm{N}_{2} \mathrm{O}$ can be converted into carbon emission equivalent according to the corresponding potential values.

\subsubsection{Direct emissions}

The amount of $\mathrm{CO}_{2}$ directly emitted during sewage treatment. In the IPCC agreement, the $\mathrm{CO}_{2}$ emissions of biogenic wastewater are not included in the total GHG emissions,according to the "Greenhouse Gas Inventory Protocol-Corporate Accounting and Reporting Standards", the total GHG emissions must be included. Yan $\mathrm{X}$ et al. investigated and studied the amount of $\mathrm{CO}_{2}$ produced during the operation of the actual sewage treatment plant, and clarified the factors affecting $\mathrm{CO}_{2}$ emissions. The calculation formula of $\mathrm{CO}_{2}$ production is:

$$
\mathrm{M}_{\mathrm{CO}_{2}}=\mathrm{Q}^{*} \mathrm{EF}_{\mathrm{CO}_{2}}
$$

In formula (1) : $\mathrm{M}_{\mathrm{CO}_{2}}-$ Biological treatment process emissions, unit:g ;

Q-Amount of sewage treated during calculation, unit: $\mathrm{m}^{3}$;

$\mathrm{EF}_{\mathrm{CO}_{2}}$-For the emission factor, refer to the $\mathrm{CO}_{2}$ emission factor of the $\mathrm{A} 2 \mathrm{O}$ process in the study by $\mathrm{Yan}$ $\mathrm{X}$ et al. [6].

With reference to the "2005 China Greenhouse Gas Inventory Research" and the "2006 National Greenhouse Gas Inventory Guidelines" published by the IPCC [7], the calculation formula for $\mathrm{CH}_{4}$ generation is as follows:

$$
\mathrm{M}_{\mathrm{CH}_{4}}=\left(\mathrm{TOW} * \mathrm{EF}_{\mathrm{CH}_{4}}\right)-\mathrm{R}_{0}
$$

In formula (2): $\mathrm{M}_{\mathrm{CH}_{4}}-\mathrm{CH}_{4}$ emissions from biological treatment process, unit: $\mathrm{kg}$;

TOW - The organic matter content in sewage during the calculation period, unit: $\mathrm{kg}$;

$\mathrm{EF}_{\mathrm{CH}_{4}}$-For the $\mathrm{CH}_{4}$ emission factor, refer to the methane emission factor of the aerobic treatment process in the study of Cai Bofeng et al. [8].

$\mathrm{R}_{0}$ - The amount of $\mathrm{CH}_{4}$ recovered during the calculation period, in $\mathrm{kg}$, if the sludge digestion facility is not in operation, the default value of $R_{0}$ is 0 .

The formula for calculating the amount of $\mathrm{N}_{2} \mathrm{O}$ produced is as follows:

$$
\mathrm{M}_{\mathrm{N}_{2} \mathrm{O}}=\mathrm{TN}^{*} \mathrm{EF}_{\mathrm{N}_{2} \mathrm{O}}
$$

In formula (3) : $\mathrm{M}_{\mathrm{N}_{2} \mathrm{O}}-\mathrm{N}_{2} \mathrm{O}$ emissions from biological treatment process, unit: $\mathrm{kg}$;

$\mathrm{TN}$-Total nitrogen removal from sewage during calculation, unit: $\mathrm{kg}$;

$\mathrm{EF}_{\mathrm{N}_{2} \mathrm{O}}-\mathrm{N}_{2} \mathrm{O}$ emission factor, refer to Yan $\mathrm{X}$ et al. [6] study.

\subsubsection{Indirect emissions}

During the operation of the sewage treatment plant, blowers, pumps, aeration equipment and other equipment consume a large amount of electricity, the carbon emissions of the purchased electricity during the production process are the indirect emissions of the sewage treatment plant, the calculation formula: 


$$
\mathrm{M}_{\mathrm{CO}_{2 \cdot \mathrm{E}}}=\mathrm{E}^{*} \mathrm{EF}_{\mathrm{CO}_{2 \cdot \mathrm{E}}}
$$

In formula (4) : $\mathrm{M}_{\mathrm{CO}_{2 \cdot \mathrm{E}}}$-Indirect $\mathrm{CO}_{2}$ emissions from power consumption, unit: $\mathrm{kg}$;

E - Power consumption, unit: $\mathrm{kw} \bullet \mathrm{h}$;

$\mathrm{EF}_{\mathrm{CO}_{2} \cdot \mathrm{E}}$ - The emission factor of electric energy consumption, in $\mathrm{kgCO}_{2} / \mathrm{kw} \bullet \mathrm{h}$, determined according to the 2015 China Regional Grid Baseline Emission Factor.

\subsubsection{Other indirect emissions}

Some drugs are used in the sewage treatment process, such as disinfectants, flocculants, etc., the formula for calculating carbon emissions of purchased drugs:

$$
\mathrm{M}_{\mathrm{CO}_{2 \cdot \mathrm{Y}}}=\sum \mathrm{Y}_{\mathrm{i}} * \mathrm{EF}_{\mathrm{CO}_{2 \cdot \mathrm{Yi}}}
$$

In formula (5) : $\mathrm{M}_{\mathrm{CO}_{2 \cdot \mathrm{Y}}}$-Indirect $\mathrm{CO}_{2}$ emissions from drug consumption, unit: $\mathrm{kg}$;

$\mathrm{Y}_{\mathrm{i}}$ - Consumption of medicine i, unit: $\mathrm{kg}$;

$\mathrm{EF}_{\mathrm{CO}_{2} \cdot \mathrm{Yi}}-\mathrm{i}$ The emission factor of $\mathrm{CO}_{2}$ consumed by medicine, unit: $\mathrm{kgCO}_{2} / \mathrm{kg}$. Each medicine should calculate its $\mathrm{CO}_{2}$ emissions with corresponding emission coefficients. For example, according to statistics, the emission factor of coagulant is $25 \mathrm{kgCO}_{2} / \mathrm{kg}$ of coagulant, and the emission factor of disinfectant is $1.4 \mathrm{kgCO}_{2} / \mathrm{kg}$ of agent.

There are some other aspects of emissions, because it is difficult to obtain GHG emission factors for calculation, but should be estimated according to the actual situation of the sewage treatment plant, determine an appropriate ratio, and include it in the total GHG emissions. After a comprehensive analysis, it is determined that other emissions are $10 \%$ of the calculable emissions, which are included in the total GHG emissions of the sewage treatment plant.

\subsection{Case analysis}

\subsubsection{Overview of urban sewage treatment plants}

The selected case is a sewage treatment plant in a northern city, using the AAO process, with a processing capacity of $30 * 10^{4} \mathrm{~m}^{3} / \mathrm{d}$, and the discharge standard is the "Urban Sewage Treatment Plant Pollutant Discharge Standard" (GB18918-2002) Class A standard. This case collects relevant activity data in 2018 , in 2018 , a total of 109.5 million tons of sewage were processed, and the quality of incoming and outgoing water was taken as the 2018 average,see Table 1 for details

Table 1. Quality of incoming and outgoing water from urban sewage treatment plants

\begin{tabular}{c|c|c|c|c}
\hline index & $\begin{array}{c}\text { Treated water } \\
\text { volume (t/a) }\end{array}$ & $\begin{array}{c}\mathrm{BOD}_{5} \\
(\mathrm{mg} / \mathrm{L})\end{array}$ & $\begin{array}{c}\mathrm{COD} \\
(\mathrm{mg} / \mathrm{L})\end{array}$ & $\begin{array}{c}\mathrm{TN} \\
(\mathrm{mg} / \mathrm{L})\end{array}$ \\
\hline \multirow{2}{*}{$\begin{array}{c}\text { Influent water } \\
\text { quality }\end{array}$} & & 139.87 & 234.56 & 45 \\
\cline { 1 - 4 } $\begin{array}{c}\text { Effluent water } \\
\text { quality }\end{array}$ & $1,095,000,000$ & 10 & 50 & 0.5 \\
\cline { 3 - 5 }
\end{tabular}

After calculation, the direct emission of $\mathrm{CO}_{2}$ from the sewage treatment process is $17049.15 \mathrm{t} / \mathrm{a}$, the $\mathrm{CO}_{2}$ equivalent of direct $\mathrm{CH}_{4}$ emission is $1859.26 \mathrm{t} / \mathrm{a}$, and the $\mathrm{CO}_{2}$ equivalent of direct $\mathrm{N}_{2} \mathrm{O}$ emission is $1166.83 \mathrm{t} / \mathrm{a}$.

The sewage treatment plant used 15 million $\mathrm{kWh}$ of electricity in 2018, the main chemical is PAM, and the annual consumption is $36.5 \mathrm{t}$.

The indirect GHG emission from electricity consumption is $16936.5 \mathrm{t} / \mathrm{a}$, and the consumption of medicines in other indirect emission produces $912.5 \mathrm{t} / \mathrm{a}$ GHG.

$10 \%$ of the determined GHG emission is used as the estimated value of other indirect emissions, and the total GHG emission of the sewage treatment plant is calculated to be $41716.66 \mathrm{t} / \mathrm{a}$.

\subsubsection{Analysis of GHG Emissions from Wastewater Treatment Plants}

The GHG emission composition of the whole plant in 2018 is shown in Table 2-5.

Table 2.The composition of GHG emissions of the whole plant in 2018

\begin{tabular}{c|c|c|c}
\hline Project & $\begin{array}{c}\text { Direct } \\
\text { emissions }\end{array}$ & $\begin{array}{c}\text { Indirect } \\
\text { emissions }\end{array}$ & $\begin{array}{c}\text { Other } \\
\text { indirect } \\
\text { emissions }\end{array}$ \\
\hline Emission t/a & 20075.24 & 16936.5 & 4704.92 \\
\hline $\begin{array}{c}\text { Percentage } \\
\text { of total plant } \\
\text { emissions }\end{array}$ & $48 \%$ & $40.6 \%$ & $11.4 \%$ \\
\hline
\end{tabular}

Table3. GHG composition of the whole plant's direct emissions in 2018

\begin{tabular}{c|c|c|c|c}
\hline Project & $\begin{array}{c}\text { Direct } \\
\text { discharge } \\
\mathrm{CO}_{2}\end{array}$ & $\begin{array}{c}\text { Direct } \\
\text { discharge } \\
\mathrm{CH}_{4}\end{array}$ & $\begin{array}{c}\text { Direct } \\
\text { discharge } \\
\mathrm{N}_{2} \mathrm{O}\end{array}$ & Subtotal \\
\hline $\begin{array}{c}\text { Emission } \\
\text { t/a }\end{array}$ & 17049.15 & 1859.26 & 1166.83 & 20075.24 \\
\hline $\begin{array}{c}\text { Percentage } \\
\text { of direct } \\
\text { emissions }\end{array}$ & $84.9 \%$ & $9.3 \%$ & $5.8 \%$ & $100 \%$ \\
\hline
\end{tabular}

Table 4. Composition of power consumption of the whole plant in 2018

\begin{tabular}{c|c|c|c|c|c}
\hline Project & $\begin{array}{c}\text { Aeration } \\
\text { unit }\end{array}$ & $\begin{array}{c}\text { Lifting } \\
\text { unit }\end{array}$ & $\begin{array}{c}\text { Sludge } \\
\text { treatment }\end{array}$ & $\begin{array}{c}\text { Pretrea } \\
\text { tment }\end{array}$ & other \\
\hline $\begin{array}{c}\text { Proportion of } \\
\text { total power } \\
\text { consumption } \\
\text { of the whole } \\
\text { plant }\end{array}$ & $52.4 \%$ & $17.8 \%$ & $8.9 \%$ & $19.1 \%$ & $1.8 \%$ \\
\hline
\end{tabular}

Table 5. The composition of other indirect GHG emissions from the whole plant in 2018

\begin{tabular}{c|c|c}
\hline Project & Drug consumption & other \\
\hline Emission $\mathrm{t} / \mathrm{a}$ & 912.5 & 3792.42 \\
\hline $\begin{array}{c}\text { Percentage of total } \\
\text { plant emissions }\end{array}$ & $2.2 \%$ & $9.1 \%$ \\
\hline
\end{tabular}

From the analysis of the GHG emission composition of the whole plant, it can be seen that the GHG directly discharged from the sewage treatment process and the 
indirect discharge generated by the power consumption are the main emission sources, accounting for $48 \%$ and $40.6 \%$ of the total discharge of the whole plant respectively. In direct emissions, direct $\mathrm{CO}_{2}$ emissions accounted for $84.9 \%$, direct emissions of $\mathrm{CH}_{4}$ accounted for only $9.3 \%$, and $\mathrm{N}_{2} \mathrm{O}$ emissions accounted for $5.8 \%$. Among the GHG indirect emissions generated by power consumption, the power consumption of the production process reached $98.2 \%$ of the power consumption of the whole plant, and the aeration unit consumed the largest power consumption, which was $52.4 \%$ of the power consumption of the whole plant, the power consumption of the three parts of the unit reached $89.3 \%$ of the power consumption of the whole plant. Among other indirect emissions, pharmaceutical consumption accounts for a relatively low proportion of the plant's GHG emissions.

From the perspective of GHG emission intensity, in 2018, the GHG discharged per cubic meter of sewage processed by the whole plant was $0.381 \mathrm{~kg} / \mathrm{m}^{3}$. Some foreign research results show that the aerobic process is used to treat domestic sewage, and its GHG emissions are $0.438 \mathrm{~kg} / \mathrm{m}^{3}$ [9] and $0.228 \sim 0.245 \mathrm{~kg} / \mathrm{m}^{3}$ [10]. The results of this study are relatively close to those of foreign studies. On the one hand, the assessment scope of this research is determined in accordance with the "Greenhouse Gas Inventory Protocol-Corporate Accounting and Reporting Standards", this standard is an internationally recognized greenhouse gas (GHG) accounting and reporting standard, which is widely accepted by companies all over the world because it follows the same so the results are relatively close. On the other hand, the amount of GHG discharged per cubic meter of sewage is affected by the quality of the incoming and outgoing water, area, working conditions, temperature, process technology, etc., it is normal that there are differences, and only this index is horizontally comparable.

In order to eliminate the influence of the difference in the quality of the incoming and outgoing water, the GHG emission per $\mathrm{kg}$ BOD removed by the sewage treatment plant is calculated, and the result is $2.064 \mathrm{kgCO}_{2} / \mathrm{kgBOD}$. Foreign countries use aerobic and anaerobic processes for wastewater treatment, and the corresponding GHG emissions are $3.31 \mathrm{~kg} / \mathrm{kg}$ [10], which is $37.6 \%$ lower than foreign studies. However, according to existing research, process design will cause gaps in the composition of GHG emissions, if anaerobic processes are used, $\mathrm{CH}_{4}$ emissions will increase significantly, and indirect emissions from drug consumption will also increase significantly. Studies have also shown that the GHG emission values for removing $\mathrm{kgCOD}$ have a large gap, which is affected by region, process, scale, and sampling time.

\section{GHG emission reduction approach}

In this example, the direct emissions of $\mathrm{CO}_{2}, \mathrm{CH}_{4}, \mathrm{~N}_{2} \mathrm{O}$ and the indirect emissions from electricity consumption in the sewage treatment process accounted for $48 \%$ and $40.6 \%$ of the total emissions of the whole plant, which are the focus of emission reduction.
For reducing direct GHG emissions, ecological treatment processes such as stabilizing ponds, constructed wetlands, building greenhouses, cultivating aquatic plants, and planting trees, use plants to absorb nutrients such as nitrogen and phosphorus in sewage, absorb $\mathrm{CO}_{2}$, and transform into plant bodies. Using the canopy area of the plant and the corresponding carbon fixation coefficient, the amount of GHG recovered by the ecological process can be determined.

In this example, $\mathrm{CH}_{4}$ emissions accounted for $9.3 \%$ of direct emissions and $4.5 \%$ of the plant's GHG emissions, the main reason is that the organic content of domestic sewage is lower than that of industrial wastewater. $\mathrm{CH}_{4}$ recovery can be used as energy combustion, on the one hand, the $\mathrm{CO}_{2}$ produced by combustion has a lower warming potential than the direct emission of $\mathrm{CH}_{4}$; on the other hand, it can save energy consumption and reduce GHG emissions. In this example, if $\mathrm{CH}_{4}$ can be recycled, it can reduce GHG emissions by $672.57 \mathrm{t} / \mathrm{a}$, and it can also reduce power consumption and reduce costs. Moreover, $\mathrm{CH}_{4}$ is a renewable energy source, which meets the requirements of the country's low-carbon circular economy development and can enjoy tax incentives.

Indirect emissions from power consumption accounted for $40.6 \%$, the working effects of blowers, water pumps, aerators and other equipment during operation are carefully designed to reduce inefficient energy consumption and save power consumption. At the same time, the sewage treatment plant should do a good job in saving water at the source and reuse the tail water to reduce GHG emissions.

\section{Conclusion}

For the purpose of providing verifiable GHG emissions from sewage treatment plants, and based on the "Greenhouse Gas Inventory Protocol-Corporate Accounting and Reporting Standards" generally accepted by the international business community, GHG emissions from sewage treatment plants are divided into direct emissions, indirect emissions and the other three parts of indirect emissions respectively explain the assessment methods and emission factors, and obtain activity data, calculate and analyze GHG emissions.

Taking the 2018 GHG emission of a sewage treatment plant in the north as an example, the GHG emission within the operation scope of the plant is $41716.66 \mathrm{t} / \mathrm{a}$. Among them, direct emissions and indirect emissions accounted for $48 \%$ and $40.6 \%$ respectively, which are the key part of emission reduction. For direct emissions, $\mathrm{CO}_{2}$ can be recovered through ecological treatment processes, and nutrients such as nitrogen and phosphorus can be absorbed, recycling $\mathrm{CH}_{4}$ can reduce emissions, save energy, and meet the national recycling, low-carbon, and eco-friendly industrial development requirements and meet environmental protection requirements. Indirect emissions from electricity consumption should be refined through process design to reduce inefficient energy consumption to reduce GHG 
emissions. Saving water at the source and reusing tail water are also effective measures to reduce emissions.

Through the investigation of case GHG emissions, analysis of GHG emissions within the scope of operation of the sewage treatment plant, scientific emission reduction measures are proposed, so that the sewage treatment plant will take a low-carbon, circular and environmentally friendly development path.

\section{References}

1. C. Sweetapple, G. Fu, D. Butler. Water Res. J. 62, 249-259(2014)

2. NBS.,MEPC..China Environmental Statistics Yearbook 2017.R.(2018)

3. SENRRUC., Xylem (China) Co., Ltd. .Research on the Path and Potential of Carbon Emission Reduction in China's Wastewater Treatment Industry.R.(2016)

4. WBCSD.,WRI..Greenhouse Gas Inventory Protocol-Corporate Accounting and Reporting Standards (Second Edition).S.(Taiwan,2005)

5. P. Falkowski, R. J. Scholes, E. Boyle, et al. Science .J.290,291-296(2000)

6. X. Yan, L. Li, J. X. Liu. JES.J.26,256-263 (2014)

7. IPCC. 2006 IPCC GuidelinesFor National Greenhouse Gas Inventories[M/OL]. (iGES, Japan,2006)

8. B. Cai, Q. Gao, Z. Li, et al. Zgrk'zyyhj.J. 25, 118124(2015)

9. J. Keller, K. Hartley. WST.J.47,43-48 (2003)

10. M. B. Shahabadi, L. Yerushalmi, F. Haghighat. WR.J. 43,2679-2687(2009). 